\title{
Towards Pollution-Control in Cyberspace: Problem Structure and Institutional Design in INTERnational Cybersecurity
}

\author{
Agnes Kasper \\ Department of Law, School of Business and Governance, \\ Tallinn University of Technology, Tallinn, Estonia \\ kasper.agnes@taltech.ee
}

Csaba Krasznay

Institute of E-government, National University

of Public Service, Budapest, Hungary

krasznay.csaba@uni-nke.hu

KASPER, Agnes; KRASZNAY, Csaba. Towards Pollution-Control in Cyberspace: Problem Structure and Institutional Design in International Cybersecurity. International and Comparative Law Review, 2019, vol. 19, no. 2, pp. 76-96. DOI: 10.2478/iclr-2019-0015.

Summary: In their contest for domination in cyberspace states engage powers of technology, money, persuasion and norms. Clashes between two competing approaches resulted in the creation of two parallel working groups in the UN that address issues of international cybersecurity, including principles, norms and laws. Although there are very few treaties that deal expressly with cyber activities, normative aspirations and frequent use of imported rules and principles from other realms to cyberspace suggest the emergence of a new cyber normative regime - though, in the short term probably short of a global treaty. The substantive content of existing and potentially applicable norms to cyberspace has been examined to a great extent, but less scholarly attention has been paid to mechanisms that can produce cooperation and compliant behavior with international norms in cyberspace. This study draws inspiration from environmental agreements from procedural aspects and we identified two environmental regimes, which address problems sufficiently similar to the challenges of international cyber security and which have been the most successful in terms of cooperation. Selection of the Montreal Protocol and REDD+ mechanism was based on the following main factors: incentives in terms of game theory, capacities of actors, information and scientific uncertainty, the time of institution creation in normative lifecycle, number of actors, and asymmetry in power and positions taken among actors. Further analysis focuses on institutional design elements in the chosen cases, and examines if or under what conditions could these be used for international normative frameworks on cyberspace.

Keywords: cybersecurity law, effectiveness of cyberlaw, cyberspace regulation, cybersecurity governance, international cyber norms. 


\section{Introduction}

\subsection{Institutions and power struggle in international cybersecurity}

Cybersecurity has become an issue attracting the attention of states and numerous forums provide platforms for discussing related problems. Such normative aspirations and frequent use of imported rules and principles from other realms to cyberspace suggest the emergence of a new cyber normative regime though, in the short term probably short of a global treaty. ${ }^{1}$ The substantive content of existing and potentially applicable norms to cyberspace has been examined to a great extent, but less scholarly attention has been paid to mechanisms that can produce cooperation and compliant behavior with international norms in cyberspace. Although cybersecurity has clearly been raised to the international agenda, the failure of the UN GGE ${ }^{2}$ (Group of Governmental Experts) in 2017 to reach a consensus report undergirded the challenges in further developments. Global interest in cybersecurity is clearly demonstrated by the new establishment of two parallel working groups in the UN (a new GGE and the Open-Ended Working Group - OEWG) serving as important forums for ongoing discussions to address questions of norms, rules and principles, confidence building measures and application of existing international law to cyberspace, nevertheless the fault-lines between the approaches of these two groups also became more visible. Therefore, the question arises, if there is interest and dialogue on cybersecurity across the globe, what would it take to connect these efforts?

Researchers and practitioners have been paying increased attention to international cybersecurity for nearly two decades. However, cybersecurity is not a clearly demarcated field of academic study ${ }^{3}$ and current practice is overwhelmingly heuristic. The UN seems to have taken a mixed approach, partially bottomup, partially top-down in addressing questions of existing and emerging threats; capacity-building; confidence-building; recommendations on the implementation of norms, rules and principles for the responsible behavior of States; and application of international law to the use of information and communication technologies. In particular, the UN General Assembly tasked the SecretaryGeneral to study, with the assistance of the GGE, these issues with a view of promoting common understanding. Korzak suggested that the expectations, and top-down approach, to achieve clear and direct statements on how international law applies to the use of ICT's prevented the consensus report in the 2016-2017

1 POLAŃSKI, Paul Przemysław. Cyberspace: A New Branch of International Customary Law? Computer Law \& Security Review, 2017, vol. 33, no. 3, pp. 371-381.

2 UN Group of Governmental Experts addressing developments in the field of information security and telecommunications in the context of international security. Available https:// www.un.org/disarmament/ict-security/ (accessed 13.09.2019)

3 EU Commission, High Level Group of Scientific Advisors, Scientific Opinion No. 2/2017. Cybersecurity in the European Digital Single Market, DG for Research and Innovation, Brussels, 24 March 2017. Available https://ec.europa.eu/research/sam/pdf/sam_cybersecurity_report.pdf (accessed 13.09.2019) 
UN GGE. ${ }^{4}$ If that is true, chances are, that the solution to engage states in global discussion on cybersecurity lies in the tailored procedure, one that is perhaps better suited to keep dissenting states within the process of norm-building on international cybersecurity rather than focusing on pronouncing end-results on an issue characterized by fault-lines.

However, with the establishment of the 2019-2021 GGE 5 and the 2019$2020 \mathrm{OEWG}^{6}$ one might also find clear evidence of a power struggle, where one group of international actors aim to exert indirect control over the other mediated by formal or informal institutions. According to Barnett and Duval, these "institutions work through the rules and procedures that define those institutions, guides, steers and constrains the actions (or nonactions) and conditions of existence of others"? Given the growing number of media reports about cyber incidents with implications at the highest level of politics, it is plausible to argue that states came to consider the full repertoire of powers, ranging from compulsory, structural and institutional to productive power, to try to control their actual or perceived adversaries. Hence, the fragmentation of UN discussions over the norms, rules, measures and laws that govern state behavior in and related to cyberspace, can be conceptualized in terms of institutional powers, where one group of actors try to shape the behavior or circumstances of others through agenda setting, proposals for formalized lines of responsibility, decisional rules and structures of dispersed dependence. While this struggle for institutional power will likely be ongoing for years to come, the repercussions from the lack of clear rules can be felt by all levels in the society, as both civilian infrastructures and military capabilities rely on digital systems, and cyber threats jeopardize economies, political systems and daily life. Besides discussing the substantive rules, it could also be worth considering what mechanisms and institutional arrangements have yielded high effectiveness in comparable fields, that is which regimes are effective in problem solving and which ones are empty shells designed to project power without tackling core issues. Hence existing research on institutional performance can inform the ongoing debate on international cybersecurity, particularly about what are those mechanisms that have yielded high level of collaboration among states in analogous fields.

\subsection{Parallels between environmental and cybersecurity problems}

There are a number of similarities between environmental problems and cybersecurity, considering for instance that access and usage of both entails

4 KORZAK, Elaine. UN GGE on Cybersecurity: The end of an Era?, The Diplomat, 31.07.2017. Available https://thediplomat.com/2017/07/un-gge-on-cybersecurity-have-china-andrussia-just-made-cyberspace-less-safe/ (accessed 13.09.2019)

5 UN GA A/RES/73/266

6 UN GA A/RES/73/27

7 MICHAEL, Barnett, DUVALL, Raymond. Power in International Politics. International Organization, vol. 59, no. 1, 2005, pp. 39-75. JSTOR, www.jstor.org/stable/3877878.: 51. 
costs; interconnectedness of factors external to but impacting on the human being; spread-out through larger spaces and across state borders (potential physical spillovers); involvement of political, economic, social and cultural aspects that go beyond the pure means of information transfer or environmental protection. ${ }^{8}$ One of the most important rules of international environmental law is the obligation to prevent transboundary environmental harm ${ }^{9}$, which underlies a core feature of environment that damage can spread irrespective of national borders - just like cyberattacks more often than not are cross-border.

While concerned with the similarities, notable differences between natural environment and cyberspace ought to be observed too. Cyberspace is outcome of human creativity and not part of the natural environment, hence the question arises as to what extent parallels are justified in designing normative regimes for cyberspace. ${ }^{10}$ Serving as non-obvious (and not perfect) analogies, international environmental regimes may be used to find arrangements and frameworks dealing with issues that are sufficiently similar in problem structure to that of international cybersecurity. International environmental regimes are mostly based on treaties, where typically techniques for dynamic arrangements and continuous or even evolutionary normative processes were used. ${ }^{11}$ The need for flexibility and capacity to adapt in international cybersecurity stems from the developing technologies, therefore environmental regimes may provide some guidance on procedural or institutional aspects in regime formation.

Having discussed the parallels to justify the environmental analogy in general, we asked the following questions: What is the problem structure of international cybersecurity? Which international environmental regimes deal with issues that have sufficiently similar problem structure? What are the institutional design features of the two most successful environmental regimes from these? Can these designs be used for institutions in international cybersecurity?

\subsection{Methodology}

Formulation of any rules and procedures for future discussion requires at least the identification of elements of the problem and the features of these elements. Drawing on methodologies devised for measuring the effectiveness of

8 MARAUHN, Thilo. Customary Rules of Environmental Law. In ZIOLKOWSKI, Katharina (ed). Peacetime Regime for State Activities in Cyberspace: International Law, International Relations and Diplomacy, NATO Cooperative Cyber Defence Centre of Excellence, 2013. pp 466-467.

9 U.S. vs Canada (Trail Smelter Arbitration Case), Decision of 16.04.1938 and 11.03.1941. http://legal.un.org/riaa/cases/vol_III/1905-1982.pdf

10 MARAUHN, Thilo. Customary Rules of Environmental Law. In ZIOLKOWSKI, Katharina (ed). Peacetime Regime for State Activities in Cyberspace: International Law, International Relations and Diplomacy, NATO Cooperative Cyber Defence Centre of Excellence, 2013. pp 466-467.

11 Ibid. 
international environmental regimes, elements of problems, or problem structures of international cyber security can be assessed by looking at incentives of actors (i.e. with the help of game theory), their capacities, information and scientific uncertainty, the time of institution creation in normative lifecycle, number of actors, and asymmetry in power and positions taken among actors. ${ }^{12}$

Institutional performance (effectiveness) depends on both problem structure and institutional design, how well they fit one another. ${ }^{13}$ In turn, institutional performance can be defined in terms of outputs, outcomes and problem solving capacities $^{14,}$ from which we are most interested in outputs, such as cooperation, collaboration and compliance. Young also notes that determinants of compliance with institutional arrangement include fairness and inclusiveness, but compliance may not always be a concern, in particular in case of non-enforceable agreements. ${ }^{15}$ This has significant implications for international cybersecurity, a field dominated by soft-law instruments and politically binding norms, placing collaboration into the spotlight, attributing less importance to issues of compliance.

After we assessed the problem structure of international cybersecurity in terms of incentives of actors (using existing game theoretical approaches), their capacities, information and scientific uncertainty, the time of institution creation in normative lifecycle, number of actors, and asymmetry in power and positions taken among actors, it was necessary to narrow down the discussion to some specific environmental regimes where analogies could be searched. To start with, the International Environmental Agreements Database Project ${ }^{16}$, which includes over 3500 instruments, was consulted with a view to identify two agreements that address issues with a problem structure comparable to the problem structure of international cybersecurity. As a preliminary step, bilateral agreements were excluded from the set due to the number of actors in cybersecurity. Next steps in regime selection involved identification of problem structures of environmental issues international regimes deal with and compare them with problem structure of international cybersecurity. This entailed systematic overview of subjects and lineages of international environmental agreements in the database, coupled with literature review on game-theoretic approaches on the given issues,

12 MITCHELL, Ronald B. Problem structure, institutional design, and the relative effectiveness of international environmental agreements. Global Environmental Politics 2006, vol. 6, no. 3, pp. 72-89.

13 UNDERDAL, Arild. One Question, Two Answers. In MILES, Edward, L, et.al. (eds.) Environmental Regime Effectiveness: Confronting Theory with Evidence, MIT Press, 2002, pp. 3-45.

14 YOUNG, Oran, R. Effectiveness of International Environmental Regimes: Existing Knowledge, Cutting-Edge Themes, and Research Strategies. Proceedings of the National Academy of Sciences 108, no. 50 (December 13, 2011) pp. 19853-60.

15 Ibid.

16 International Environmental Agreements (IEA) Database Project. Available https://iea. uoregon.edu/ (accessed 13.09.2019) 
addressing incentives of parties. Having shortlisted the regimes and agreements, lastly it was necessary to define how to operationalize the requirement of regime success for the current purposes and context.

Here distinction was made between the formal output, outcome and impact of regimes. Output refers to the rules constituting the regime and the set of consequences flowing from them, in other words regime formation and level of collaboration. ${ }^{17}$ Underdal explained in addressing effectiveness of environmental regimes that outcome and impact materialize as changes in human behavior and in biophysical environment respectively - which probably have to do more with the substance of the actual norms (are they right?), but also depend on the design of the regime. ${ }^{18}$ Intuitively we may ask whether there is a significant difference between outcome and impact in measuring regime effectiveness in international cybersecurity, since cyberspace depends on humans for its very existence, unlike nature. However, as in the introduction we set focus on procedural aspects, rather than substantive content of (potential) cyber norms, it became clear that for the purposes of this research effectiveness or success of regimes is evaluated in terms of output, i.e. collaboration. Underdal argued that collaboration can be measured and analyzed in terms of depth, inclusiveness and stringency of rules, which in combination with other factors, makes a positive, but modest contribution to the effectiveness of international environmental regimes. ${ }^{19}$ Hence, we found that it would be straightforward to look at inclusiveness of selected regimes, i.e. number of participants, and combine it with a requirement of relatively high level of collaboration, making no requirements about stringency of rules for the time being as cybersecurity norms are presumed to be emerging. Applying these criteria, two environmental regimes were selected for further analysis.

Hence, we choose to focus on problem structure and institutional design as they seem to be linked with institutional performance and thus cooperation where relevant. Further Chapter 2 is dedicated to characterizing aspects and conceptualizing the problem structure of international cybersecurity. In Chapter 3 we identify and explain two successful environmental regimes that represent the closest matches to cybersecurity in terms of problem structure. We focus on the mechanics on how the selected environmental regimes operate, describes procedural aspects that have been praised for contributing to regime effectiveness in terms of cooperation of actors, and proposes relevant implications/applications for international cybersecurity. In Chapter 4 the authors sum up and indicate areas for further research.

17 UNDERDAL, Arild. One Question, Two Answers. In MILES, Edward, L, et.al. (eds.) Environmental Regime Effectiveness: Confronting Theory with Evidence, MIT Press, 2002, pp. 3-45.

18 Ibid.

19 Ibid. 


\section{Problem structure of international cybersecurity}

\subsection{Number and capacities of actors}

In international cybersecurity global threats have been addressed in bilateral relations, but the existence of multilateral forums ${ }^{20}$ clearly indicates that cybersecurity is a multi-actor problem. Here a question on private actors can be raised, since there is ongoing discourse about their role in cybersecurity. ${ }^{21}$ To clarify our approach, we assume that the main players in international cybersecurity are states, and although private actors may be influential, they contribute to creation of international norms only indirectly.

National or organisational strategies are changing. On the surface everyone talked about preventive measures until 2016. Now, many countries openly admit offensive capacity building. ${ }^{22}$ We are in the age of cyber deterrence. Of course, only a few countries have more than just words and countries which are believed to have the most developed cyber warfare capabilities are US, Russia, China, Israel and UK, but North-Korea and Iran are also claimed to have such cyber forces. ${ }^{23}$ Some sources indicate that around 30 countries are now focusing on offense in the cyber domain ${ }^{24}$, but deterrent capacity needs years to be built up. The cyber-defence capabilities are also evolving and most Western nations have stepped up their defences in the last few years. ${ }^{25}$

20 See for example OSCE, OECD, EU, UN, NATO.

21 Note for example Jason Healey "The best use of government resources is to reinforce those doing the best work already. Our critical infrastructure companies are on the front lines, and together with major vendors and cybersecurity companies have far more defensive capabilities than our military."in CARBERRY, Sean D. Why the private sector is key to cybersecurity? FCW: The Business of Federal Technology, 01.03.2017. Available https://fcw. com/articles/2017/03/01/why-the-private-sector-is-key-to-cybersecurity.aspx (accessed 13.09.2019)

22 Reuters reported that the "United States, Britain, Germany, Norway, Spain, Denmark and the Netherlands are drawing up cyber warfare principles to guide their militaries on what justifies deploying cyber attack weapons more broadly" as well as mentioned the intention of Estonia to establish a cyber command that covers the full range of cyber operations. EMMOTT, Robin. NATO mulls 'offensive defense' with cyber warfare rules. Available https://www.reuters.com/article/us-nato-cyber/nato-mulls-offensive-defense-with-cyberwarfare-rules-idUSKBN1DU1G4 (accessed 13.09.2019)

23 BREENE, Keith. Who are the cyberwar superpowers? World Economic Forum, 04.05.2016. Available https://www.weforum.org/agenda/2016/05/who-are-the-cyberwar-superpowers/ (accessed 13.09.2019)

24 Joint Statement by US director of National Security James Clapper, undersecretary of defense for intelligence Marcel Lettre, and NSA and US Cyber Command director Admiral Mike Rogers, at a hearing on foreign cyber threats by the Senate Armed Services Committee. 5 January 2017. Available https://www.armed-services.senate.gov/imo/media/doc/ Clapper-Lettre-Rogers_01-05-16.pdf (accessed 13.09.2019)

25 THEILER, Olaf. The New threats: the cyber dimension. NATO Review, Available https:// www.nato.int/docu/review/2011/11-september/cyber-threads/en/index.htm (accessed 13.09.2019) 


\subsection{Time of institution creation in the normative lifecycle}

International attention was drawn to network warfare capabilities of the US in the first Gulf War, crashing the Iraqi Integrated Air Defence System in Operation Desert Storm in 1991. Relevance of cyber security (in normative terms mostly focus on cybercrime) has been raised to international levels since late 90's with Russian Federation's proposal for a UN resolution in 1998 and the 2001 Council of Europe's Convention on Cybercrime. More significant and widespread attention of governments was triggered by the 2007 Estonian incidents, which raised awareness about the new vulnerabilities of societies and eventually inspired the adoption of national cybersecurity strategies worldwide. Most of current strategies are still first generation, however there are several second and third generation strategies in developed countries. In the year 2009 actual discussion began on international information security in the UN and in 2010 the UN Group of Governmental Experts published a first report, followed by others in 2013, and $2015 .{ }^{26}$ Other forums were also opened to discuss issues of cybersecurity, such as the 2013 Munich Security Conference, which was a clear indication of militarization of cyberspace. The evidence reviewed here seems to suggest that we are at the beginning of the normative lifecycle of international cybersecurity.

\subsection{Asymmetries and positions taken by stakeholders}

A recent study by Bigelow illustrated the nature of cyberspace threats and pointed out that military operation and nations are dependent upon a complex set of supporting military, governmental and commercial networks and systems, thus it should not be presumed that these infrastructures can be available for conducting cyber operations, which in turn makes these systems a target. ${ }^{27}$ Cyberattacks are not easily attributable, although often difficulties may be rather political, legal or practical, than technical. However, attribution may not be strictly necessary when the attacked organizations may lack the legal authority or appropriate tools to strike back directly or in kind. ${ }^{28}$ In addition there can be significant delay between the initiation and detecting cyberattacks. Asymmetries are also identifiable as a digital divide both on regional as well as global levels. ${ }^{29}$

As a consequence of the number of stakeholders in cyberspace, states do not and cannot exert their control to the same degree as they can with other domains. Hence organizations and individuals have no other choice, but to find

26 A/65/201 of 30 July 2010; A/68/98 of 24 June 2013; A/70/174 of 22 July 2015

27 BIGELOW, Brad. Mission Assurance: Shifting the Focus of Cyber Defence. IN RÕIGAS, Henry et. al. $9^{\text {th }}$ International Conference on Cyber Conflict: Defending the Core, Proceedings, 2017, CCDCOE, IEEE, Tallinn. p. 47.

28 Ibid.

29 KERIKMÄE, Tanel, SÄRAV, Sandra. Legal Impediments in the EU to New Technologies in the Example of E-Residency. Baltic Journal of Law \& Politics, 2016, vol. 8. no. 2, pp. 71-90. 
security solutions themselves. ${ }^{30}$ On the other hand cyberspace is also a power multiplicator for small and non-state groups to get their messages across to a global audience and it also offers opportunities to disrupt the largest adversaries by new means of attack. ${ }^{31}$ Therefore cyberspace can be characterized by offense dominance. ${ }^{32}$ However, it is also a mutable and human-made environment, which can be shaped by different governance measures ${ }^{33}$, including legal norms - that remains the domain of states.

\subsection{Incentives of actors}

For institutions to work, the questions of who, what, why, when and how questions should be answered. First, as Rid and Buchanan put it "the security of the state may depend ascribing agency to an agent", hence attribution is fundamental. ${ }^{34}$ Uncertainties are associated not only with identification sources of incidents, but also goals and background of actors. ${ }^{35}$ Second, cybersecurity questions revolve around code and information - the resources for interaction in cyberspace - their sharing and distribution (or lack thereof), which pertains to the question of what is the object of the institutional framework. Based on fundamentally different ideological attitudes states currently disagree whether free flow of information in cyberspace is desirable or considered as a threat ${ }^{36}$, while most seem to agree that malicious code should be controlled. However, any of this control is a matter of cooperation and collaboration, that must include information sharing.

Strategic interactions in political science, economics, etc. between decision-makers have been modelled by game theoretical games extensively since the mid-20 $0^{\text {th }}$ century. Game theory provides useful tools for gaining insight to incentives of actors in different contexts of decision-making. For these reasons we look into what game models have been used to address challenges of attribution and information sharing in international cybersecurity, but we also emphasize that these serve this research only to characterize elements and control for

30 RATTRAY, Gregory, J. An Environmental Approach to Understanding Cyberpower. In KRAMER, Franklin, D. et. al. (eds). Cyberpower and National Security, Potomac Books, 2009. p. 257.

31 Ibid. p. 268.

32 Ibid. p. 272.

33 KERIKMÄE, Tanel, RULL, Addi (Eds). The Future of Law and eTechnologies, 2016, Springer-Verlag Heidelberg.

34 RID, Thomas, BUCHANAN, Ben. Attributing Cyber Attacks. Journal of Strategic Studies, 2015, vol. 38, no.1-2, pp. 4-37.

35 VALUCH, Jozef; GÁBRIŠ, Tomáš; HAMULÁK, Ondrej. Cyber Attacks, Information Attacks and Posstmodern Warfare. Baltic Journal of Law \& Politics 2017, vol. 10, no. 1, p. 67.

36 HENRIKSEN, Anders. The end of the road for the UN GGE process: The future regulation of cyberspace. Journal of Cybersecurity, 2019, vol. 5, no. 1, p. 5. 
variation in problem structure in order to enable comparison with international environmental regimes. Hence solutions to these games will not be sought here.

Edwards et. al. draws attention to strategic components of attribution and blame for cyberattacks in international context. ${ }^{37}$ The authors present a Bayesian game-theoretic model (non-cooperative games with incomplete information), the Blame game, which consist of two players (A and B), where player A, the attacker is either vulnerable or not vulnerable, player $B$, the victim is either knowledgeable or not knowledgeable. This analysis demonstrated that it may be rational for nations to tolerate cyberattacks of mild consequences, especially if put in larger geopolitical context. ${ }^{38}$ Bayesian sequential defender-attacker game was also used in a strategic analysis by Kujwaski to address deterrence in cyberspace. ${ }^{39}$ Effectiveness of dynamic games of incomplete information has also been exemplified in a paper by Heitzenrater et. al dealing with deterrence. ${ }^{40}$

Although the JASON report has concluded that "there are no laws of nature for cybersecurity and it is an applied science that is informed by the mathematical constructs of computer science" ${ }^{41}$, Casey et. al. maintain that cybersecurity as a discrete field is not free from underlying order and structure and they emphasized informational asymmetry and claim to show that "by suitably modelling of agents of the system and the utilities they wish to achieve in cyberspace, and under the standard assumptions of common knowledge of rationality, [using signalling games, so non-cooperative games with incomplete information] a suitable law can be imposed on the system, which can evolve to a desirable equilibrium" ${ }^{42}$ Moore, Friedman and Procassia designed two games applicable in national security context, "vulnerability stockpiles" and "cyber hawk", with imperfect information as fundamental property and explored the trade-offs between attack and defence of information systems. ${ }^{43}$

37 EDWARDS, Benjamin Edwards, FURNAS, Alexander, FORREST, Stephanie, AXELROD, Robert. Strategic Aspects of Cyberattack, Attribution, and Blame. Proceedings of the National Academy of Sciences 114, no. 11, pp. 2825-30.

38 Ibid.

39 KUJAWSKI, Edouard. A Probabilistic Game-Theoretic Method to Assess Deterrence and Defense Benefits of Security Systems: Deterrence and Defense Benefits of Security Systems. Systems Engineering 2016, vol. 19, no. 6, pp. 549-66.

40 HEITZENRATER, Chad, TAYLOR, Greg, SIMPSON, Andrew. When the Winning Move Is Not to Play: Games of Deterrence in Cyber Security. In KHOUZANI, MHR, et.al. (eds). Decision and Game Theory for Security: 6th International Conference, GameSec 2015, London, UK, November 4-5, 2015, Proceedings, Cham: Springer International Publishing, 2015, pp. 250-69.

41 JASON, The MITRE Corporation, Science of Cyber-Security, Technical Report, JSR-10102, November 2010, Available https://fas.org/irp/agency/dod/jason/cyber.pdf (accessed 13.09.2019)

42 CASEY, William. et al. Cyber Security via Signaling Games: Toward a Science of Cyber Security. In NATARAJAN, R.(eds) Distributed Computing and Internet Technology. ICDCIT 2014. Lecture Notes in Computer Science, vol 8337. Springer, Cham pp. 34-42.

43 MOORE, Tyler, FRIEDMAN, Allan, PROCACCIA, Ariel, D. Would A'cyber Warrior'protect 
A comprehensive study of Sinha et.al. reported on practical application of repeated Stackelberg security games (again non-cooperative incomplete information games) in fields ranging from critical infrastructure protection, through interdicting illegal flow of drugs, weapons and money, to protecting endangered wildlife, forests and fisheries, and security in cyberspace. ${ }^{44}$ However, the main problem with the Stackelberg security games in the context of international cyber security is that it presumes hierarchical control. In legal terms this would contradict to the principle of sovereign equality of states, but it may also reflect actual power relations in technological, social, military, economic, political or other terms. Nevertheless, in institutional setting hierarchical control can be presumed based on the pacta sunt servanda (agreements must be kept) principle and/or the authority of institutions.

In summary, this section provides key aspects of the problem structure of international cybersecurity. It appears that international cybersecurity is a young, multi-actor field characterized by offence dominance and interdependence, and incentives of actors can be described in terms of non-cooperative incomplete information games - in particular signalling games and Stackelberg security games. The next chapter is moving to identify environmental regimes that address issues with similar problem structures.

\section{Environmental regime analogies for international cybersecurity}

\subsection{Montreal Protocol}

\subsubsection{Problem structure of ozone layer depletion addressed by the Montreal Protocol}

The 1987 Montreal Protocol on Substances that Deplete the Ozone Layer is a proxy to the Vienna Convention for the Protection of the Ozone Layer and is considered as perhaps the most successful international environmental agreement with 197 parties. $^{45}$

As to the problem structure, ozone layer depletion is a truly global problem making it multi-actor and interdependent issue. Also, at the time of the adoption of the Montreal Protocol there was no scientific consensus on certain aspects of ozone depletion, therefore institutions were created early in the normative lifecycle. Asymmetries between players were manifested during negotiations by

Us: Exploring Trade-Offs between Attack and Defense of Information Systems. In Proceedings of the 2010 Workshop on New Security Paradigms (ACM, 2010), pp. 85-94.

44 SINHA, Arunesh et al. From Physical Security to Cybersecurity. Journal of Cybersecurity, November 17, 2015. See also BASILICO, Nicola, DE NITTIS, Giuseppe, GATTI, Nicola. A Security Game Model for Environment Protection in the Presence of an Alarm System. In KHOUZANI, MHR, et.al. (eds). Decision and Game Theory for Security: 6th International Conference, GameSec 2015, London, UK, November 4-5, 2015, Proceedings, Cham: Springer International Publishing, 2015), pp.192-207;

45 VELDERS, Guus, JM, et al. The Importance of the Montreal Protocol in Protecting Climate. Proceedings of the National Academy of Sciences, 2007, vol. 104, no. 12, pp. 4814-19. 
developing nations' reluctance to participate and arguing that it is a problem that they did not create. Ozone layer being a public good, conflict between individual and collective rationality can be resolved by intervention. ${ }^{46}$ Hence incentives were necessary to convince them to become parties, while the actual costs of participation were relatively low (cheap alternative substances are available to those harming the ozone layer).

Parallels can be drawn between the incentives of states in the problem of reducing emission of harmful substances to the atmosphere and the problems of attribution and information sharing in international cybersecurity. This is also supported by at least two studies that apply signalling games to international environmental agreements, in particular mentioning the Montreal Protocol and the Kyoto Protocol. ${ }^{47}$ In case of environmental problems the information asymmetry lies in two regions' differing preferences for environmental quality (which is initially manifested in willingness to participate in a regime) and uncertainty about the type of the region, hence cooperation becomes feasible only when the region has credibly revealed its type. ${ }^{48}$ In international cybersecurity player types can be defined in different ways, for instance defence-oriented/cyber aggressor or controlling/laissez faire or pro-disclosure/pro-secrecy, etc. However, credible revelations about one's own type entails risks, such as sharing sensitive information thereby exposing vulnerabilities. Hence the Montreal Protocols success in achieving universal participation can be informative in addressing the collaboration problem in international cybersecurity.

\subsubsection{Incentives for participation in the Montreal Protocol}

Vienna Convention as a framework for negotiating international regulations on ozone-depleting substances was established in 1985 and the Montreal Protocol was adopted in 1987. It takes the precautionary approach, while aims to control equitably the emission of certain substances (CFCs) by phasing out production and consumption. The procedures factor into technical and economic considerations, in particularly it is emphasized that developing countries need special provisions. Three key aspects are pointed out here, first is incentivizing participation by establishing a joint fiscal mechanism, second creating incentives for new

46 However the Montreal Protocol did not present the prisoner's dilemma because key nations would gain from unilateral action.

47 ESPÍNOLA-ARREDONDO, Ana, MUÑOZ-GARCÍA, Félix. Free-Riding in International Environmental Agreements: A Signaling Approach to Non-Enforceable Treaties. Journal of Theoretical Politics 2011, vol. 23, no. 1 (January 2011), pp. 111-34. JAKOB, Michael, LESSMANN, Kai. Signaling in International Environmental Agreements: The Case of Early and Delayed Action. International Environmental Agreements: Politics, Law and Economics 2012, vol. 12, no. 4, pp. 309-325.

48 JAKOB, Michael, LESSMANN, Kai. Signaling in International Environmental Agreements: The Case of Early and Delayed Action. International Environmental Agreements: Politics, Law and Economics 2012, vol. 12, no. 4, pp. 309-325. 
technology, and allowing for a 10 years grace period for developing countries. ${ }^{49}$ Compliance issues are considered in a separate document, according to which noncompliant parties may be discovered through the secretariat, complaints or self-recognition. The relatively weak compliance mechanisms, however, do not seem to be problem, since the benefits clearly outweigh the costs of participating and affordable alternatives to controlled substances exist. Parson found that the innovative aspect of the Protocol lies in its adaptiveness: "in articulating its original goal, an adaptive regime incorporates the insight that what is needed to attain the goal cannot be fully known at the outset, but must be progressively adjusted over time". ${ }^{50}$ Pursuant to Article 6 of the Montreal Protocol assessment panels were set up in 1989, thereby slicing the larger problem into smaller pieces and signalling the delegates' intention not to try to assert direct control. Now three panels, Technology and Economic Assessment Panel (TEAP), Scientific Assessment Panel (SAP) and Environmental Effects Assessment Panel (EEAP) carry out periodic assessments at least every 4 years, and they operate in the basic spirit of separating assessment from politics. This mechanism "effectively removed certain bounded scientific and technical questions from the domain of political controversy to a separate forum where they can be resolved on scientific or technical grounds". ${ }^{51}$ Hence the protocol is progressive in its scope, started with the easiest parts of the problem first and gradually added to the list of controlled substances new ones, thus continuing international process is essential. Sunstein also pointed out that the saliency of the problem and that agreement was very strongly in the interest of the main sponsoring state, the US ${ }^{52}$, and there was no incentive to defect, contributed to the success. ${ }^{53}$

The implications for international cybersecurity could be that scientific uncertainty and lack of strong enforcement mechanisms may not be an obstacle for regime formation. Yet, regime formation need not be in the form of binding international agreements, and keeping in mind the complexity and nature of the subject matter, any form of cooperation can be understood as a regime here. Main factors that deserve attention from the context of Montreal Protocol are the strong incentives of sponsors (which are necessarily connected with

49 UNEP, 2014 Assessment Report for the Technology and Economic Assessment Panel, 2015. Available http://42functions.net/Assessment_Panels/TEAP/Reports/TEAP_Reports/ TEAP_Assessment_report_2014.pdf (accessed 13.09.2019)

50 PARSON, Edward, A. The Montreal Protocol: The First Adaptive Global Environmental Regime? In PRESTRE et al. (eds.) Protecting the Ozone Layer: Lessons, Models, and Prospects, Kluwer Academic Publishers, 1998. p. 127.

51 PARSON, Edward, A. The Montreal Protocol: The First Adaptive Global Environmental Regime? In PRESTRE et al. (eds.) Protecting the Ozone Layer: Lessons, Models, and Prospects, Kluwer Academic Publishers, 1998. p. 130.

52 US has already complied with the Montreal Protocol before it was made and cost-benefit analysis carried out indicates that the Stag Hunt may be the game that appropriately models its incentives in this case.

53 SUNSTEIN, Cass, R. Of Montreal and Kyoto: A Tale of Two Protocols. Harward Environmental Law Review, 2007, vol. 31. p. 8. 
domestic contexts) and incremental, progressive mechanisms to expand the scope of discussion. For these, identifications of core problem areas within the broader area of cybersecurity would be necessary and it may worth consideration to set up independent and dedicated panels to carry out assessments within their competence. This may practically mean breaking down the work of the UNGGE or OEWG into discrete fields and task them with assessing the status of international cybersecurity from their particular scientific perspective. Another solution could be to bring under the same umbrella efforts in international organizations which deal with aspects of international cybersecurity within their mandate. This mechanism would not necessarily involve broad participation, but surely needs to be representative of those most affected, hence a distinction can be made between developed and developing countries in terms of information society. This way the signal could be sent to the international community from participating states that no direct control is asserted, each can benefit from the scientific discussion and progress, keeping political controversies to separate forums. It appears that one of the most pressing issues to start with, and which has implications both for information sharing and attribution, could be the reduction of software vulnerabilities by incentivizing security by design, as well as coordination of responsible vulnerability disclosure practices and establishment of high-level cyber hygiene standards.

\subsection{UNFCCC REDD+}

\subsubsection{Problem structure of deforestation and the UNFCCC REDD+}

Much of the literature on international environmental problems, which use the game-theoretical approach indeed points to stag hunt and prisoners' dilemma games. ${ }^{54}$ Rodrigues et.al. have analyzed deforestation problem with game theoretical approach and found that the stag hunt or prisoner's dilemma is likely to occur under persistent or circulating supply of resources. ${ }^{55}$ Signalling games can also be applied to the UNFCCC similarly to the Montreal Protocol discussed above. However, the UNFCCC is a framework, which also includes a program where information plays a crucial role and the Stackelberg games have been applied in practice. The 2005 REDD programs originally aimed to reduce greenhouse gas emissions from forests were superseded in 2013 by the more complex REDD+ and it is considered successful in that it has engaged the most affected states. One of the main issues directly addressed is forest degradation. Key component of the programme are decisions on modalities for measuring, reporting and verification (MRV).

54 KÄGI, Wolfgang. Economics of Climate Change: The Contribution of Forestry Projects Springer, 2000.

55 RODRIGUES, António. A Game Theoretical Model of Deforestation in Human-environment Relationships. Journal of Theoretical Biology 2009, vol. 258, no. 1, pp. 127-34. 
These mechanisms are also comparable to issues in international cybersecurity in that they address protection of valued assets, i.e. forests and trees against illegal logging, which may correspond to confidentiality, integrity and availability attributes of data and systems in cybersecurity. However, it is noted that imposing tighter grip creates clandestine markets - both in commodities, such as illegally cut trees or ivory, etc. as well as it may do the same for instance for vulnerabilities (although underground markets are more than flourishing in this area) and other informational assets, such as personal information, if similarly regulated.

\subsubsection{Flexibility of enforcement in REDD+}

REDD+ programme focuses on developing countries and establishes resultbased finance and information sharing mechanisms. It creates a financial value for the carbon stored in forests by offering incentives for developing countries to reduce emissions from forested lands and invest in low-carbon paths to sustainable development. ${ }^{56}$ Although REDD+ is just a set of guidelines on national actions, implementation, measurement and reporting, the essential elements of national programmes and reports are also set out to ensure consistency and compatibility for evaluation. Decision 14/CP.19 Modalities for measuring, reporting and verifying ${ }^{57}$ is a key instrument in the system of REDD+ mechanisms, since it establishes guarantees for transparency, consistency, comprehensiveness and accuracy of data collection and flow, but also takes into account state sovereignty. In essence a country seeking payments from relevant funds shall supply a technical annex, which undergoes a peer-review by the technical team of experts ${ }^{58}$, and published on the UNFCCC web platform ${ }^{59}$.

These solutions in REDD+ may teach us a few lessons for international cybersecurity. First, REDD+ is one of those regimes, where zero-sum narratives are transformed into nonzero-sum solutions, or as David Takacs put it: deep equity zero-sum policies.$^{60}$ In other words, degradation of environment in one area is compensated (by payments) from another area, and offsetting occurs by economic and ecological planning on the macro level, where resources come from economies that developed without paying for the environmentally destruc-

56 http://www.unredd.net/about/what-is-redd-plus.html

57 FCCC/CP/2013/10/Add.1 of 31.01.2014, Report of the Conference of the Parties in its nineteenth session, held in Warsaw from 11 to 23 November 2013, Addendum.

58 Section 12-13.

59 Section 14.

60 TAKACS, David. Deep Equity, Zero-sum environmentalism, and a sustainable planet. IN: BAKER, Shalanda, Helen, et.al. Beyond Zero-Sum Environmentalism (May 8, 2017). Environmental Law Reporter, 2017, vol. 47, no. 4. Available at SSRN: https://ssrn.com/ abstract=2945666 (accessed 13.09.2019) 
tive externalities. ${ }^{61}$ In this offsetting system the "currencies" of climate change are $\mathrm{CO} 2$ emissions and financial resources.

In cyber context this logic can be applied if measurable "currencies" with which we calculate winners and losers of cybersecurity - or a particular segment thereof, such as information sharing - are (re)defined. This may be information, cooperation, financial resources, capacities, capabilities, trust, etc., In addition our notions of short- and long-term beneficiaries in terms of dualistic frameworks for expressing gains and losses, should be integrated into a holistic, multi-level framework. In more practical terms this would mean, for example that the short- and long-term benefits of using the currencies of cybersecurity (increasing transparency, investment into capabilities, specific cooperation, such as common exercises, etc.) should be measured in one framework, and on international, national and organizational levels (maybe even user level). This would allow us to design mechanisms, where offsetting is possible, for example negative externalities of information sharing can be compensated for by certain investments. There is of course the obvious problem of objectively measuring, reporting and verifying cybersecurity, more precisely the lack of counterfactuals. However, the exact same problem exists in measuring the effectiveness of environmental agreements, which is why the example of REDD+ is noteworthy as it flexibly defines only elements to be included in technical reports when applying for support.

\section{Conclusions}

This paper highlighted several similarities between cyberspace and global environment. Although in both areas several threat agents are independent or semi-dependent from states, their activities shall be controlled by local and international norms. In cyberspace, this cannot be feasible without global cooperation. First step should be trust building, followed by information sharing as a next step. Environmental regimes provided good examples how these results can be achieved.

Pioneers of measuring success of environmental regimes have shown that accurate problem definition and tailored institutional design are determinants of regime success, where compliance can be one of the indicators thereof and more emphasis is on collaboration. We admit that this is a simplified account of reality and we do not know the exact relationships between these elements. However, drawing on the research on effectiveness of environmental regimes we elaborated on the problem structure of international cybersecurity and found parallels in environmental regimes that give us a good basis for finding ways forward in conceptualizing emerging institutional arrangements for the first.

61 Ibid. 
We found that international cybersecurity is a young, multi-actor field characterized by offence dominance and interdependence, and incentives of actors can be described in terms of non-cooperative incomplete information games, particularly signalling games and Stackelberg security games. Since environmental problems are also often distributed in time and space, we looked for particular environmental issues with properties similar to that of cybersecurity. Analogies from international environmental regimes were identified and we used the Montreal Protocol and UN-REDD+ to indicate strategies to make steps forward in the discussion about institutional mechanisms for international cybersecurity.

Non-obvious analogies to environmental regimes, the negotiations preceding them, and procedures can teach us some lessons. First, some political challenges can be overcome by understanding the underlying interests that play into the process of international discussion on cybersecurity and designing procedures that accommodate these interests. For example, the Montreal Protocol provided a long transitional period for initially reluctant or uncertain states. This transitional period was also necessary for relevant science to consolidate and provide high level of certainty, but also allowed national-level politics to catch-up. When it comes to cybersecurity and international norms, we should take into account that the probably most influential scientific work in this field, the Tallinn Manual 2.0 has been published in the beginning of 2017 and states are still wrestling with what to think of it as a whole and the proposed rules. Signing up for a certain interpretation of an existing international norm or advocating the formation of a new one may have its implications on national level, but these are yet to be addressed. Hence it is not a surprise that the UN GGE could not produce a consensus report in 2017 and the international community has now become ever more divided on some fundamental questions represented by two parallel and competing working groups in the UN, since states are still struggling with defining themselves, their interests and values in cyberspace. Also beyond this, power struggles and geopolitics are at play, which cannot be separated from the discussion, since here is where the main fault-lines lie. ${ }^{62}$ Hence discussing global cyber stability is a multi-factor exercise, where there is no room for self-imposed rules, but rather start should be from building on strengths - and one of these is that there is increasing interest and participation in the forums addressing cybersecurity. Therefore, focus ought to be on keeping the discussion on-going and design procedures that allow different approaches and identify the perceptions of main pillars of state sovereignty in cyberspace. The mechanisms used in the Montreal Protocol was successful in just that, by creating no incentives to defect.

62 SABBAH, Cedric. Pressing Pause: A New Approach for International Cybersecurity Norm Development. In MINARIK, T. et al. (eds). Proceedings of $10^{\text {th }}$ International Conference on Cyber Conflict - Cycon X: Maximising Effects, NATO CCDCOE, 2018, pp. 263-282. 
Secondly, salience of international cybersecurity issues greatly varies among states, as the depths of the submissions to the UN Secretary-General on information security and the comprehensiveness of national cybersecurity strategies (or lack of it) testify. The importance states attribute to these issues can have an impact on their preferences towards discussions and potential collaboration formation procedures. Hence, on the example of the Montreal Protocol, a multitrack, multi-speed discussion design that accommodates the different underlying state incentives (incl. internationally and domestically) may allow a continuous and more harmonious development towards norm building in international cybersecurity.

Thirdly, the REDD+ was successful in separating political from technical issues. Technology is at the heart of international cybersecurity. By definition the implementation of norms (or lack of it) can be assessed from purely technological perspective, although in practice there may be legal, political or other obstacles. Yet, one of the key components here is transparency, which allows measurement. Both are lacking features and given the sensitive nature, a benchmark should be designed to draw the line between necessary information sharing and beyond. In practical terms this may start with definition of standard of proof relating to international cyber incidents and moving towards more sophisticated mechanisms with integrated reward mechanisms for objective measurements.

Fourthly, states may consider other, perhaps complementary principles to territoriality. It is now a clear trend that rather than location of data, possession and access to data is what really matters ${ }^{63}$. Hence, in practice we are already moving away from the territorial-based view of sovereignty. It is still highly questionable how exactly the implementation of these new legal norms will succeed, but their existence points to the perception that fundamental changes are needed. Therefore, the somewhat old, but novel in their kind provisions of addressing liabilities (i.e. Cybercrime Convention) are a departure point for addressing the questions of enforcement.

We have also understood that other regimes may also be useful for the purposes of learning from their procedures, such as the Convention on Long-Range Transboundary Air Pollution or regimes controlling the usage of radioactive material, which may be particularly relevant in the light of the recently discovered Spectre and Meltdown flaws. It is highly probable that nations have or will have malware that exploits this bug and they will use against each other. These are cases where there may not be a good technical solution for organisations worldwide and non-technical solutions are needed. In environmental security, regulation of radioactive materials can be an example that can be used under strict regulation for civilian as well as military purposes, which may be considered as an analogy for designing successful collaborative frameworks in international cybersecurity.

63 See for example US CLOUD Act and EU e-evidence framework proposals. 
Limitation of our research lays in the narrow focus, excluding from the scope non-state actors and selective analysis of only a few cases. There are considerable factors that add to the complexity of this field, as now it is perceived as a national security issue. It should also be noted that the literature on incentives in gametheoretical terms also mainly focus only on technical issues and seems to lack comprehensive accounts for addressing state level games in international cyber security. This gap should be addressed by interdisciplinary research synthesizing observations from international relations, security studies and technology, and addressing issues about states' sovereign interests, international law and cyber operations, etc.

Processes like the work of the UN GGE and OEWG and confidence building efforts on different international forums should be coupled with analytical research and can lead to the highly desirable state of stability in cyberspace. Current, "not peace but not yet war" state blocks global development. As ICT technologies are undoubtedly transforming the world we are living in, we shouldn't contaminate the virtual world with malware or cyber weapons as we did with the biophysical environment.

\section{References}

BASILICO, Nicola, DE NITTIS, Giuseppe, GATTI, Nicola. A Security Game Model for Environment Protection in the Presence of an Alarm System. In KHOUZANI, MHR, et.al. (eds). Decision and Game Theory for Security: 6th International Conference, GameSec 2015, London, UK, November 4-5, 2015, Proceedings, Cham: Springer International Publishing, 2015), pp.192-207;

BIGELOW, Brad. Mission Assurance: Shifting the Focus of Cyber Defence. IN RÕIGAS, Henry et. al. $9^{\text {th }}$ International Conference on Cyber Conflict: Defending the Core, Proceedings, 2017, CCDCOE, IEEE, Tallinn.

BREENE, Keith. Who are the cyberwar superpowers? World Economic Forum, 04.05.2016. Available https://www.weforum.org/agenda/2016/05/who-are-the-cyberwar-superpowers/ (accessed 13.09.2019)

CARBERRY, Sean D. Why the private sector is key to cybersecurity? FCW: The Business of Federal Technology, 01.03.2017. Available https://fcw.com/articles/2017/03/01/whythe-private-sector-is-key-to-cybersecurity.aspx (accessed 13.09.2019)

CASEY, William. et al. Cyber Security via Signaling Games: Toward a Science of Cyber Security. In NATARAJAN, R.(eds) Distributed Computing and Internet Technology. ICDCIT 2014. Lecture Notes in Computer Science, vol 8337. Springer, Cham pp. $34-42$.

EDWARDS, Benjamin Edwards, FURNAS, Alexander, FORREST, Stephanie, AXELROD, Robert. Strategic Aspects of Cyberattack, Attribution, and Blame. Proceedings of the National Academy of Sciences 114, no. 11 (March 14, 2017) pp. 2825-30.

EMMOTT, Robin. NATO mulls 'offensive defense' with cyber warfare rules. Available https://www.reuters.com/article/us-nato-cyber/nato-mulls-offensive-defense-withcyber-warfare-rules-idUSKBN1DU1G4 (accessed 13.09.2019)

ESPÍNOLA-ARREDONDO, Ana, MUÑOZ-GARCÍA, Félix. Free-Riding in International Environmental Agreements: A Signaling Approach to Non-Enforceable Treaties. 
Journal of Theoretical Politics, 2011, vol. 23, no. 1, pp. 111-34.

EU Commission, High Level Group of Scientific Advisors, Scientific Opinion No. 2/2017. Cybersecurity in the European Digital Single Market, DG for Research and Innovation, Brussels, 24 March 2017. Available https://ec.europa.eu/research/sam/pdf/sam cybersecurity_report.pdf (accessed 13.09.2019)

HEITZENRATER, Chad, TAYLOR, Greg, SIMPSON, Andrew. When the Winning Move Is Not to Play: Games of Deterrence in Cyber Security. In KHOUZANI, MHR, et.al. (eds). Decision and Game Theory for Security: 6th International Conference, GameSec 2015, London, UK, November 4-5, 2015, Proceedings, Cham: Springer International Publishing, 2015, pp. 250-69.

HENRIKSEN, Anders. The end of the road for the UN GGE process: The future regulation of cyberspace. Journal of Cybersecurity, 2019, vol 5, no. 1.

JAKOB, Michael, LESSMANN, Kai. Signaling in International Environmental Agreements: The Case of Early and Delayed Action. International Environmental Agreements: Politics, Law and Economics, 2012, vol. 12, no. 4, pp. 309-25.

JASON, The MITRE Corporation, Science of Cyber-Security, Technical Report, JSR10-102, November 2010, Available https://fas.org/irp/agency/dod/jason/cyber.pdf (accessed 13.09.2019)

KÄGI, Wolfgang. Economics of Climate Change: The Contribution of Forestry Projects Springer, 2000.

KERIKMÄE, Tanel, RULL, Addi (Eds). The Future of Law and eTechnologies, 2016, Springer-Verlag Heidelberg.

KERIKMÄE, Tanel, SÄRAV, Sandra. Legal Impediments in the EU to New Technologies in the Example of E-Residency. Baltic Journal of Law \& Politics, 2016, vol. 8., no. 2, pp. 71-90.

KORZAK, Elaine. UN GGE on Cybersecurity: The end of an Era?, The Diplomat, 31.07.2017. Available https://thediplomat.com/2017/07/un-gge-on-cybersecurityhave-china-and-russia-just-made-cyberspace-less-safe/ (accessed 13.09.2019)

KUJAWSKI, Edouard. A Probabilistic Game-Theoretic Method to Assess Deterrence and Defense Benefits of Security Systems: Deterrence and Defense Benefits of Security Systems. Systems Engineering, 2016, vol. 19, no. 6, pp. 549-566.

MARAUHN, Thilo. Customary Rules of Environmental Law. In ZIOLKOWSKI, Katharina (ed). Peacetime Regime for State Activities in Cyberspace: International Law, International Relations and Diplomacy, NATO Cooperative Cyber Defence Centre of Excellence, 2013.

MICHAEL, Barnett, DUVALL, Raymond. Power in International Politics. International Organization, 2005, vol. 59, no. 1, pp. 39-75. JSTOR, www.jstor.org/stable/3877878.

MITCHELL, Ronald B. Problem structure, institutional design, and the relative effectiveness of international environmental agreements. Global Environmental Politics 2006, vol. 6 , no. 3, pp. 72-89.

MOORE, Tyler, FRIEDMAN, Allan, PROCACCIA, Ariel, D. Would A'cyber Warrior'protect Us: Exploring Trade-Offs between Attack and Defense of Information Systems. In Proceedings of the 2010 Workshop on New Security Paradigms (ACM, 2010), pp. 85-94.

PARSON, Edward, A. The Montreal Protocol: The First Adaptive Global Environmental Regime? In PRESTRE et al. (eds.) Protecting the Ozone Layer: Lessons, Models, and Prospects, Kluwer Academic Publishers, 1998. 
POLAŃSKI, Paul Przemysław. Cyberspace: A New Branch of International Customary Law? Computer Law \& Security Review, 2017, vol. 33, no. 3, pp. 371-381.

RATTRAY, Gregory, J. An Environmental Approach to Understanding Cyberpower. In KRAMER, Franklin, D. et. al. (eds). Cyberpower and National Security, Potomac Books, 2009.

RID, Thomas, BUCHANAN, Ben. Attributing Cyber Attacks. Journal of Strategic Studies, 2015, vol. 38, no. 1-2, pp. 4-37.

RODRIGUES, António. A Game Theoretical Model of Deforestation in Human-environment Relationships. Journal of Theoretical Biology, 2009, vol. 258, no. 1, pp. 127-34.

SABBAH, Cedric. Pressing Pause: A New Approach for International Cybersecurity Norm Development. In MINARIK, T. et al. (eds). Proceedings of $10^{\text {th }}$ International Conference on Cyber Conflict - Cycon X: Maximising Effects, NATO CCDCOE, 2018, pp. 263-282.

SINHA, Arunesh et al. From Physical Security to Cybersecurity. Journal of Cybersecurity, November 17, 2015.

SUNSTEIN, Cass, R. Of Montreal and Kyoto: A Tale of Two Protocols. Harward Environmental Law Review, 2007, vol. 31.

TAKACS, David. Deep Equity, Zero-sum environmentalism, and a sustainable planet. IN: BAKER, Shalanda, Helen, et.al. Beyond Zero-Sum Environmentalism (May 8, 2017). Environmental Law Reporter, Vol. 47, No. 4, 2017. Available at SSRN: https://ssrn. com/abstract $=2945666$ (accessed 13.09.2019)

THEILER, Olaf. The New threats: the cyber dimension. NATO Review, Available https://www.nato.int/docu/review/2011/11-september/cyber-threads/en/index.htm (accessed 13.09.2019)

UNDERDAL, Arild. One Question, Two Answers. In MILES, Edward, L, et.al. (eds.) Environmental Regime Effectiveness: Confronting Theory with Evidence, MIT Press, 2002, pp. 3-45.

UNDERDAL, Arild. One Question, Two Answers. In MILES, Edward, L, et.al. (eds.) Environmental Regime Effectiveness: Confronting Theory with Evidence, MIT Press, 2002, pp. 3-45.

VELDERS, Guus, JM, et al. The Importance of the Montreal Protocol in Protecting Climate. Proceedings of the National Academy of Sciences, 2007, vol. 104, no. 12, pp. 4814-4819.

VALUCH, Jozef, GÁBRIŠ, Tomáš, HAMULÁK, Ondrej. Cyber Attacks, Information Attacks and Posstmodern Warfare. Baltic Journal of Law \& Politics 2017, vol. 10, no. 1, pp. 63-89.

YOUNG, Oran, R. Effectiveness of International Environmental Regimes: Existing Knowledge, Cutting-Edge Themes, and Research Strategies. Proceedings of the National Academy of Sciences 108, no. 50, pp. 19853-60. 